\title{
Development of a gas micro-preconcentrator for the analysis of explosive traces: study and characterization of various adsorbing materials
}

\author{
Yehya MOHSEN ${ }^{1}$, Jean-Baptiste SANCHEZ ${ }^{1}$, Franck BERGER ${ }^{1}$, Houda LAHLOU ${ }^{1}$, Igor \\ BEZVERKHYY ${ }^{2}$, Vanessa FIERRO ${ }^{3}$, Guy WEBER ${ }^{2}$, Alain CELZARD ${ }^{3}$, Jean-Pierre BELLAT ${ }^{2}$ \\ ${ }^{1}$ Institut Chrono-environnement, UMR CNRS 6249, Université de Franche Comté, 16 Route de Gray, \\ 25030 Besançon, France \\ Yehya.mohsen@univ-fcomte.fr \\ ${ }^{2}$ Laboratoire Interdisciplinaire Carnot de Bourgogne, UMR CNRS 5209, Groupe Adsorption sur \\ Solides Poreux, Université de Bourgogne, 9 Avenue Alain Savary, 21078 Dijon, France \\ ${ }^{3}$ Institut Jean Lamour, Département 2 : Chimie et Physique des Solides et des Surfaces, UMR CNRS \\ 7198, Nancy Université, UPV-Metz, ENSTIB, 27 rue Philippe Séguin, 88051 Épinal cedex 9, France
}

\begin{abstract}
Actually, the rapid detection of explosive agents in air has become a real need. In this context, the aim of this research work is to develop a micro-fluidic platform integrated on a silicon substrate for the monitoring of explosive traces in air. This platform is composed by a micro-preconcentrator followed by a chromatographic micro-column and a tin oxide- based sensor. The target molecule studied is the orthonitrotoluene (ONT) known as a simili vapor of trinitrotoluene (TNT). The present study is focused on the gas micro-preconcentrator performances, and in particular on the choice of the adsorbent. Various adsorbents such as activated carbons, polymer and hydrophobic zeolite were then studied in order to identify the best material to be used in the gas preconcentrator.
\end{abstract}

Keywords: Trinitrotoluene, Gas micro-preconcentrator, Activated carbon, Zeolite, Polymer, Explosive agents detection, Tin oxide gas sensor.

\section{Introduction}

In order to promote the safety of people in public areas, it's important to prevent terrorism actions, by identifying the presence of explosive agents in some zones of risk, such as railways and airports. This requires the implementation of performing detection equipments that offer at the same time their portability, selectivity and low detection limit [1]. Concerning the last point, there is a growing demand for the use of preconcentrating devices coupled with the detection systems [2]. In particular, the choice of the adsorbing material is the key factor behind the performance of the gas preconcentrator. Ideally, the suitable adsorbent must have a high adsorption capacity, a fast adsorption and desorption rate, as well as a good stability and durability in use [3].

This study is focused on the development of 3D micro-preconcentrator and especially on the selection of an appropriate adsorbent for the preconcentration of a simili compound of trinitrotoluene (TNT). In this case, we carried out a series of in-depth analyses that were performed on a set of adsorbents. First, we used some standard material analysis techniques to validate the choice of the adsorbent. Then, we tested the micropreconcentrator with a chromatographic column in front of a chemical gas sensor.

\section{Materials and Methods}

1. Adsorbent preparation

Herein, we studied three families of adsorbents:

$>$ Activated carbons (ACs) prepared from two commercial precursors. One from granular Norit with a grain size of $10-20 \mu \mathrm{m}$ labelled "N", and three from Kraft lignin with a grain size below $40 \mu \mathrm{m}$ and labelled " $\mathrm{KL}_{1}$ ", " $\mathrm{KL} \mathrm{L}_{2}$ " and " $\mathrm{KL}_{3}$ ". These carbons were chemically activated with $\mathrm{KOH}$ in an ascending $\mathrm{KOH}$ to precursor weight ratio, respectively, and were then submitted to a thermal treatment at a temperature around $700^{\circ} \mathrm{C}$, as detailed elsewhere [4].

> A polymer: Tenax TA (80/100 mesh) was purchased from Sigma Aldrich and labelled "TA".

$>$ A hydrophobic zeolite obtained from Degussa zeolite products: Faujasite DAY, so-called "FAUY", with a particle size of 3-5 $\mu \mathrm{m}$ and a high $\mathrm{SiO}_{2} / \mathrm{Al}_{2} \mathrm{O}_{3}$ ratio. 
2. Micro-preconcentrator fabrication The micro-preconcentrator consisted of a three dimensional structure with a $5 \mathrm{~mm}$-wide, $10 \mathrm{~mm}$-long and $400 \mu \mathrm{m}$-deep microcavity equipped with zigzag micropillars etched in a silicon substrate using deep reactive ion etching (DRIE) (Fig. 1). A platinum microheater was deposited by sputtering on the backside of the silicon cavity to allow the heating of the structure during the desorption step.

The structure was finally sealed with a Pyrex tape by anodic bonding and the fluidic connections were realized by sticking two capillary tubes into the inlet and outlet microchannels of the structure.

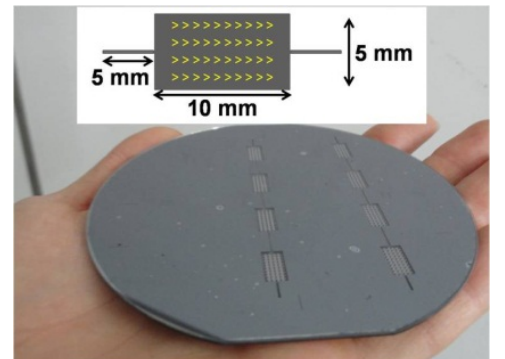

Fig.1. Picture of 8 micro-preconcentrators on a 4" silicon wafer

In order to fill the micro-preconcentrator with the adsorbent, a suspension was prepared by dispersing the adsorbent grains in heptane at a concentration about $25 \mathrm{~g} . \mathrm{L}^{-1}$ and was inserted into the microcavity by depression. The solvent was then evaporated at room temperature.

\section{Adsorbent selection}

Due to the difficulty to handle the TNT vapor in the laboratory, this was replaced by a simili vapor, orthonitrotoluene (ONT). The selection of the most appropriate adsorbent for ONT was realized in three steps. For these tests, the orthonitrotoluene was generated from a permeation tube, with a permeation rate of $12.4 \times 10^{3} \quad$ ng. $\mathrm{min}^{-1}$. Different calibrated concentrations of the analyte in synthetic air or nitrogen were obtained by adjusting the oven temperature and the gas flow.

a. Adsorbent characterization

In order to evaluate their porous properties and to determine their adsorption capacities (adsorption/desorption velocity, desorption temperature), the different adsorbents were first characterized by nitrogen adsorption manometry (ASAP 2020 Micromeritics) and then by thermogravimetric analysis (TGA 92).

The porous properties (surface area, pore volume and average pore diameter) of the adsorbents were determined from the corresponding nitrogen adsorption-desorption isotherms at $77 \mathrm{~K}$ with an automatic instrument. For that purpose, the samples were first outgassed at high temperature to eliminate the molecules adsorbed at room temperature and their adsorption data at relative pressures ranging from $10^{-5}$ to 0.99 were recorded.

For the thermogravimetric analysis, $4 \mathrm{mg}$ of the adsorbent powder was first out-gassed at $300^{\circ} \mathrm{C}$ under $100 \mathrm{~mL} \cdot \mathrm{min}^{-1}$ of $\mathrm{N}_{2}$. Then, every sample was exposed to a flow of $100 \mathrm{~mL} \cdot \mathrm{min}^{-1}$ of ONT at room temperature. The ONT concentration was $22 \mathrm{ppm}$ in $\mathrm{N}_{2}$. The total desorption was realized by heating the sample at $230^{\circ} \mathrm{C}$ under $100 \mathrm{~mL} \cdot \mathrm{min}^{-1}$ of $\mathrm{N}_{2}$.

After the determination of the best adsorbing materials to be used in the micropreconcentrator, the purpose was to detect a low concentration of orthonitrotoluene using a system formed by the coupling of the micropreconcentrator, a chromatographic column and a chemical gas sensor $\left(\mathrm{SnO}_{2}\right)$.

b. Preconcentration capacity

The preconcentrators were tested towards ONT by coupling them to a GC column in front of a tin oxide gas sensor system. These analysis were performed by adsorbing $22 \mathrm{ppm}$ of ONT balanced in air at $84 \mathrm{ml} . \mathrm{min}^{-1}$ during $5 \mathrm{~min}$ and desorbing it at a temperature around $250^{\circ} \mathrm{C}$ during $5 \mathrm{~min}$. Elution was performed by heating the column at $75^{\circ} \mathrm{C}$. The response of the system was evaluated by recording the change of the instantaneous conductance of the metal oxide gas sensor versus time.

The preconcentration factor was defined in our case as the ratio of the height of the desorption peak to the height of the reference peak without adsorbent. The preconcentration factors of the different devices were evaluated in the same conditions and normalized per milligram of adsorbent toward $22 \mathrm{ppm}$ of ONT.

The adsorbents with the best preconcentration capacity were used to determine the detection limit of the system towards ONT. Air was used at the same time as a diluting and carrier gas. A calibration of the system response versus the initial concentration of ONT, ranging between $365 \mathrm{ppb}$ and $22 \mathrm{ppm}$, was performed with and without the preconcentrator.

\section{Results and discussion}

\section{Adsorbent characterization}

a. Nitrogen adsorption/desorption isotherms Figure 2 presents the adsorption isotherms of the zeolite FAUY, the carbons $\mathrm{N}, \mathrm{KL}_{1}, \mathrm{KL}_{2}$ and $\mathrm{KL}_{3}$ and Tenax TA. While table 1 summarizes the textural parameters of the different adsorbents derived from their isotherms.

From these first results, we observed, at very low relative pressures $\left(P / P_{0}<0.01\right)$, that the isotherms of the carbons and the zeolite showed a sharp increase in the adsorbed volume when increasing the pressure. This common behavior indicates the existence of a 
narrow microporosity (lower than $1 \mathrm{~nm}$ ). The isotherms of the zeolite FAUY and the carbon $\mathrm{KL}_{1}$ are type I following the IUPAC classification, which is characteristic of microporous materials. We observed also that the zeolite FAUY belongs to the wide pore zeolites having a pore diameter of $0.75 \mathrm{~nm}$ and a large distribution of mesopores (2-15 nm). $\mathrm{KL}_{2}$ and $\mathrm{KL}_{3}$ showed a higher nitrogen uptake at $\mathrm{P} / \mathrm{P}_{0}<0.01$, wider elbows ending at relative pressures near to 0.5 and higher total nitrogen uptakes than the carbons $\mathrm{N}$ and $\mathrm{KL}_{1}$. This explains their large surface area and their important mesoporosity. The isotherms of carbons $\mathrm{N}, \mathrm{KL}_{2}$ and $\mathrm{KL}_{3}$ showed a hysteresis cycle, which is related to the phenomenon of capillary condensation proving the presence of mesopores. While the isotherm of the Tenax TA indicates its macroporous structure and its low surface area of about $20 \mathrm{~m}^{2} \cdot \mathrm{g}^{-1}$ (table 1 ).

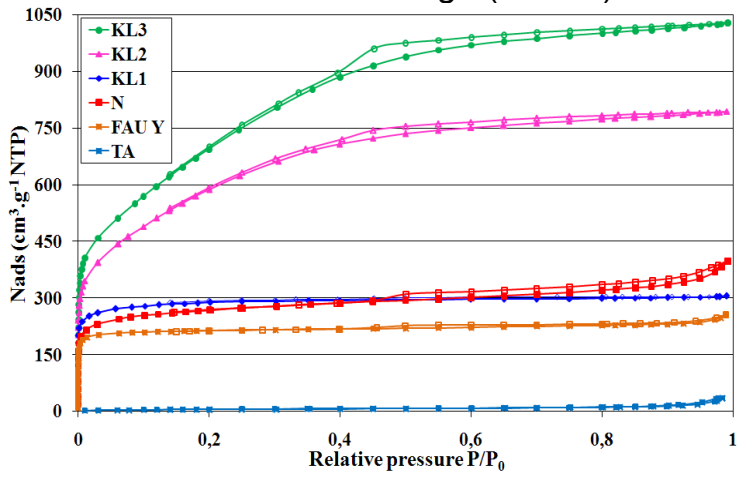

Fig. 2: Nitrogen adsorption-desorption isotherms at $77 \mathrm{~K}$ of all adsorbents

Tab. 1: Textural properties of adsorbents: surface area, pore volume and average pore diameter

\begin{tabular}{|c|c|c|c|c|c|c|}
\hline Adsorbents & $\begin{array}{c}\mathrm{S}_{\mathrm{BET}} \\
\left(\mathrm{m}^{2} / \mathrm{g}\right)\end{array}$ & $\begin{array}{c}\mathrm{V}_{\mathrm{T}} \\
\left(\mathrm{cm}^{3} / \mathrm{g}\right)\end{array}$ & $\begin{array}{c}\mathrm{V}_{\text {micro } \mathrm{HK}} \\
\left(\mathrm{cm}^{3} / \mathrm{g}\right)\end{array}$ & $\begin{array}{c}\mathrm{V}_{\text {meso }} \\
\left(\mathrm{cm}^{3} / \mathrm{g}\right)\end{array}$ & $\begin{array}{c}\mathrm{D}_{\text {micro }} \\
(\mathrm{nm})\end{array}$ & $\begin{array}{c}\mathrm{D}_{\text {meso }} \\
(\mathrm{nm})\end{array}$ \\
\hline $\mathrm{KL}_{1}$ & 976 & 0.472 & 0.391 & 0.081 & 0.50 & 4.25 \\
\hline $\mathrm{KL}_{2}$ & 2150 & 1.229 & 0.535 & 0.694 & 0.59 & 3.66 \\
\hline $\mathrm{KL}_{3}$ & 2572 & 1.593 & 0.629 & 0.964 & 0.6 & 3.74 \\
\hline $\mathrm{N}$ & 916 & 0.617 & 0.334 & 0.283 & 0.52 & 4.96 \\
\hline $\mathrm{FAUY}$ & 717 & 0.398 & 0.30 & 0.098 & 0.75 & $2-15$ \\
\hline $\mathrm{TA}$ & 20 & 0.056 & $/$ & 0.053 & $/$ & 16 \\
\hline
\end{tabular}

b. Thermogravimetric analysis

This study allowed to determine the initial desorption temperature of ONT, the adsorption and desorption rate, and the adsorption capacities of the adsorbents in order to choose the best one for the ONT adsorption.

The histogram presented in figure 3 summarizes the results concerning the total adsorbed amounts, and the adsorption and desorption rate obtained with the different adsorbents after being exposed to $22 \mathrm{ppm}$ of ONT during 17 hours. The rate was calculated from the slope of the branches of adsorption and desorption. On one hand, the results showed that the carbons $\mathrm{KL}_{2}$ and $\mathrm{KL}_{3}$ present a high adsorption capacity for ONT. In fact, these carbons have a high surface area and a pore size compatible with the dimension of the target molecule $(0.9 \mathrm{~nm})$. In this case, the amount of adsorbed pollutant was around $152 \mathrm{mg} \cdot \mathrm{g}^{-1}$ and the adsorption velocity was $8.5 \times 10^{-6} \mathrm{mg} . \mathrm{s}^{-1}$, for both analytes. While the desorption velocity was $9.5 \times 10^{-4}$ for $\mathrm{KL}_{2}$, and $8.2 \times 10^{-4} \mathrm{mg}^{-\mathrm{s}^{-1}}$ for $\mathrm{KL}_{3}$. On the other hand, no adsorption of ONT was observed with the carbon $\mathrm{KL}_{1}$ due to its microporosity definitely too narrow for trapping the analyte.

The carbon Norit presented a high adsorption capacity but a low desorption rate, which suggests the formation of a chemical bonding of the ONT molecule at the Norit surface.

The faujasite showed a high adsorption capacity and a high desorption rate as well. Finally, Tenax TA showed a low adsorption capacity due to its lower surface area.

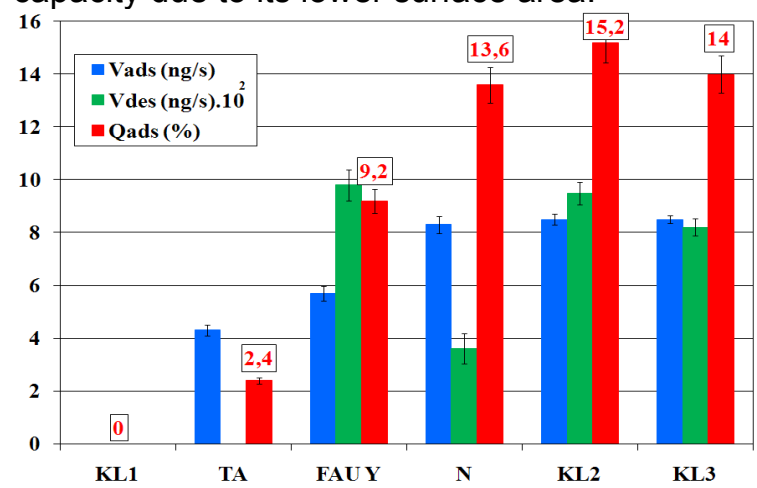

Fig. 3: Histogram of adsorbents according to their adsorbed amount (\%) during 17 hours and their adsorption and desorption rates

This study allowed to select 4 adsorbents: the carbons $\mathrm{N}, \mathrm{KL}_{2}, \mathrm{KL}_{3}$ and the zeolite $\mathrm{FAUY}$. The next step was to test these adsorbents in the micro-preconcentrator.

\section{Preconcentration tests}

Figure 4 shows an example of a cross sectional view of the micro-preconcentrator filled with a layer of activated carbon. The presence of the micropillars inside the microcavity promoted the fixing of the adsorbent and allowed getting a homogeneous distribution of the grains inside the microstructure.

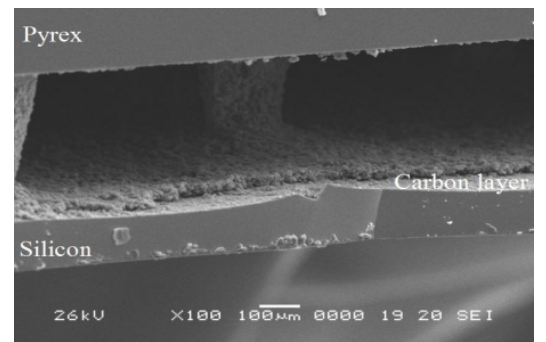

Fig. 4: SEM image of the carbon layer deposited into the preconcentrator cavity 
The set of materials selected from the previous study (FAUY, $\mathrm{KL}_{2}, \mathrm{KL}_{3}$ and $\mathrm{N}$ ) was tested with the micro-preconcentrator placed in front a GC column and a tin oxide based-gas sensor. In our working conditions, the elution of ONT occurred at a retention time of $7.5 \mathrm{~min}$. The preconcentration factors of the different devices normalized per milligram of adsorbent toward $22 \mathrm{ppm}$ of ONT appear in the histogram of figure 5 . These results confirmed the higher affinity of activated carbon $\mathrm{KL}_{3}$ towards ONT due to its higher mesoporosity. Nevertheless this material showed a residual desorption peak of ONT due to its incomplete desorption during the first heating. On the other hand, the zeolite showed a good adsorption capacity and a complete desorption of ONT in less than 5 min. The materials $\mathrm{KL}_{2}$ and Norit were finally discarded owing to their lower adsorption capacity worsened by an incomplete desorption of ONT. FAUY and $\mathrm{KL}_{3}$ were retained for further selection tests.

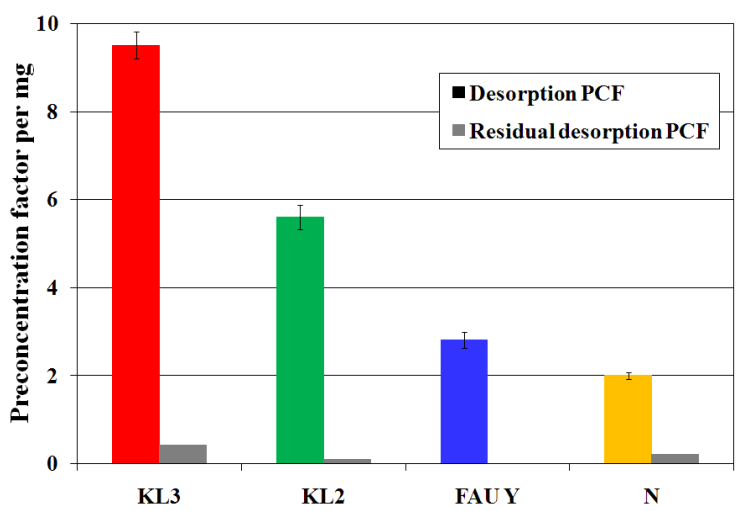

Fig. 5: Normalized preconcentration factor (PCF) for various adsorbents.

- Figure 6 shows the chromatograms obtained with and without the adsorbents FAUY and $\mathrm{KL}_{3}$ at different initial concentrations of ONT. We observed that the detection limit of the system without the adsorbent was below $365 \mathrm{ppb}$.

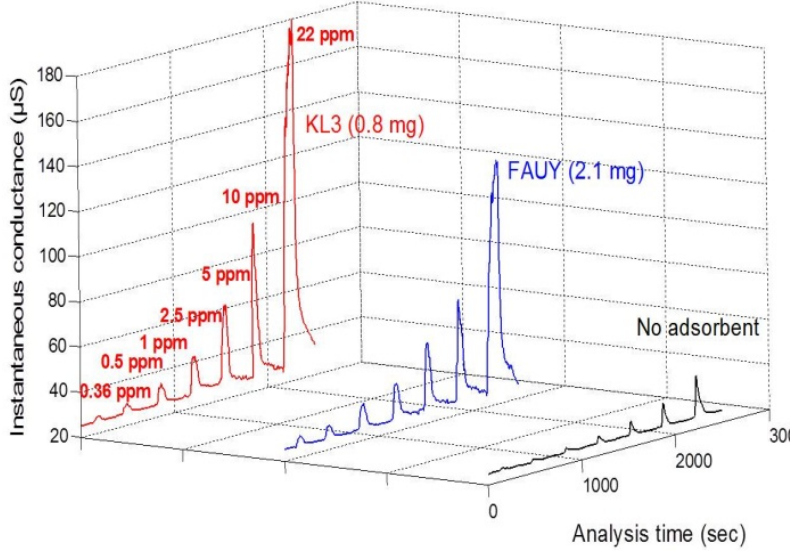

Fig. 6: Chromatograms with and without micropreconcentrator at different initial ONT concentrations
The use of a micro-preconcentrator with a deposited layer of carbon $\mathrm{KL}_{3}$ or zeolite FAUY was found to clearly improve the detection limit of the system by at least three and two orders of magnitude, respectively (Fig. 7)

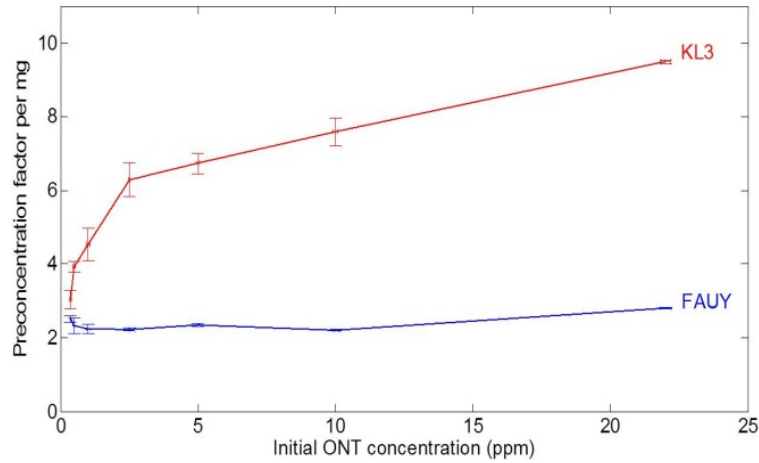

Fig 7: Normalized preconcentration factors of ONT with KL3 and FAUY versus initial ONT concentration

\section{Conclusions}

We successfully developed a 3D gas micropreconcentrator for the detection of ONT using a chromatographic characterization system. The adsorbent selection was performed on the basis of a thorough characterization of the structural characteristics and adsorption kinetics of a set of materials. The device was then validated by analyzing its performance towards ONT. The best preconcentration performance was attributed to a highly mesoporous carbon and a hydrophobic zeolite combining high adsorption capacity and fast desorption kinetics. The results confirmed the possibility to enhance the detection limit of the system at some ppb by involving the selected adsorbents inside the preconcentrator.

\section{Acknowledgements}

The authors gratefully acknowledge the staff of the MIMENTO clean room of the Femto-ST institute for their support during the fabrication of the micro-preconcentrator.

\section{References}

[1] J. S. Caygill et al., Current trends in explosive detection techniques, Talanta 188, 14-29 (2012); doi:10.1016/j.talanta.2011.11.043

[2] I. Voiculescu et al., Microfabricated chemical preconcentrators for gas-phase microanalytical detection systems, Trends in Analytical Chemistry 107, No 4 (2008); doi: 10.1016/j.trac.2008.01.016

[3] A. Freni et al., Adsorbent coatings for heat pumping applications: Verification of hydrothermal and mechanical stabilities, Applied Thermal Engineering, (2011); in press, doi:10.1016/j.applthermaleng.2011.07.010

[4] V. Fierro et al., Methodical study of the chemical activation of Kraft lignin with $\mathrm{KOH}$ and $\mathrm{NaOH}$, Microporous \& Mesoporous Materials 101, 419431 (2007); doi:10.1016/j.micromeso2006.12.004 